\title{
Health surveillance among a team of Australian health workers assisting tsunami victims in Aceh, Indonesia
}

\author{
Jeremy M. McAnulty ${ }^{\mathrm{A}, \mathrm{B}, \mathrm{C}}$ and Michael Flynn ${ }^{\mathrm{B}}$ \\ ${ }^{\mathrm{A} N S W}$ Department of Health. \\ ${ }^{\mathrm{B}}$ On behalf of: Combined Australian Surgical Team - Aceh. \\ ${ }^{\mathrm{C}}$ Corresponding author. Email: \\ jeremy.mcanulty@doh.health.nsw.gov.au
}

\begin{abstract}
Objective: To determine the extent and nature of health-related behaviours and outcomes among members of the first foreign medical team to arrive in Aceh, following the Boxing Day tsunami in 2004. Methods: A cross sectional survey of team members 4 weeks after return from Aceh. Results: Compliance with antimalarial chemoprophylaxis and insect repellent was high while in Aceh, but only one-third completed the course of chemoprophylaxis. The provision of prepackaged food and water was likely to have prevented enteric disease. Members reported mosquito bites, fatigue, sunburn, headache and anxiety about earthquakes. Conclusions: Provision of prepackaged food and water, preventive measures and information to members may be important in avoiding illness in such teams.
\end{abstract}

Following the Asian tsunami of 26 December 2004, the Australian Government dispatched several medical teams to affected regions to assist in the care and treatment of injured people. Two of these teams (Teams Alpha and Bravo) were combined and sent to Aceh, a province in Indonesia. This group became the Combined Australian Surgical Team - Aceh (CASTA).

CASTA had 28 members. It was led by one of the authors (Michael Flynn) and included a deputy leader, two logisticians (fire officers), two medical logisticians, two paramedics, an infectious diseases doctor, an emergency doctor, four anaesthetists, two general surgeons, two orthopaedic surgeons, four theatre nurses, four emergency nurses and two public health doctors. CASTA team members gathered in Sydney on Wednesday 29 December and were briefed on the general situation and likely health risks. They were provided with daily doxycycline tablets for malaria prophylaxis and offered immunoglobulin if they were not known to be immune to hepatitis A and typhoid vaccine if they had not been vaccinated against typhoid in the previous 3 years. CASTA left from the Royal Australian Air Force Base, Richmond, that afternoon and stayed in Jakarta overnight.

On 30 December CASTA members flew to Banda Aceh (a city in Aceh) and stayed overnight near the airfield in tents. On 31 December, trucks carried team members to the Fakinah Hospital, a private hospital that had experienced only mild earthquake damage and was not affected by water from the tsunami. Fakinah Hospital had been reopened and had a small number of surgical staff who had been flown in from other parts of Indonesia. However, medical supplies and staffing levels were limited.

CASTA team members provided an acute surgical and medical service at Fakinah Hospital, Kesdam Hospital (also in Banda Aceh, and to which surgical teams travelled each day) and Sigli Hospital (outside Banda Aceh, and to which a small team travelled in the latter part of their time in Aceh, to assist a Médecins Sans Frontières surgical team). From 31 December 2004 to 6 January 2005, the CASTA team cared for patients attending the Fakinah Hospital emergency department, providing medical care to around 75 inpatients at the Fakinah Hospital, performing surgical procedures for over 130 patients and providing treatments to many other patients at all three hospitals. CASTA left Banda Aceh for Jakarta on Friday 7 January 2005, departed Jakarta on 8 January and returned to Australia on the morning of 9 January.

While in Banda Aceh, team members were provided with bottled water and prepackaged food (in the form of military ration packs) brought from Australia, bed nets, insect repellent and other personal protective equipment. Team members were reminded to use these on a daily basis.

This study aimed to identify whether CASTA team members complied with the preventive advice above and also to assess team members' health status while on the mission and in the 4 weeks following their return to Australia. In addition, team members' suggestions were sought for improving prevention for future such missions. 


\section{Methods}

CASTA team members agreed to participate in a cross sectional survey at one of the regular evening debriefs while they were in Banda Aceh. A questionnaire was developed in consultation with team members. It covered their demographic characteristics, past experience of overseas relief missions, use of prophylactic materials (such as repellents and sun block), symptoms experienced on mission and comments on how their health could have been improved. The questionnaire was emailed to all team members on 4 February 2005 (4 weeks after leaving Aceh), and two follow up emails were sent to members soliciting completed questionnaires. Team members faxed or emailed responses to the other author (Jeremy McAnulty) who deidentified, collated and tallied the responses.

\section{Results}

In total, $22(79 \%)$ of the 28 CASTA members returned completed questionnaires. The main functions of these 22 respondents were: clinical (17), public health/administra- tion (three) and support/logistics (two). Average age was 48 years (range 35 to 58 years) and $16(73 \%)$ were male. Ten $(45 \%)$ reported previous experience in overseas relief missions.

Table 1 displays the number and per cent of respondents who reported compliance with the preventive measures while they were on the mission, as well as their reported health problems and concerns. No one reported vomiting, diarrhoea or fever. Of the seven reported injuries, two were directly health care associated (eye splash and needle stick), and five were less direct (strained back, small scratches, stab wound while making holes in bottles, scratches from a cat that led to a course of rabies vaccination, and a painful knee).

\section{Health after returning home}

Eight respondents $(36 \%)$ reported that they had missionrelated health problems on return. These included skin problems such as itchiness, ringworm and presumed solar sensitivity to doxycycline (three); sleep, concentration or

Table 1. Number and percentage of Combined Australian Surgical Team - Aceh (CASTA) members reporting compliance with preventive measures, and health problems and concerns while on mission, January $2005(n=22)$

\begin{tabular}{lcc}
\hline & $n$ & $\%$ \\
\hline Compliance with preventive measures & & \\
Received immunoglobulin on day of departure & 10 & 45 \\
Received typhoid vaccine on day of departure & 13 & 59 \\
Took doxycycline daily while on mission & 22 & 100 \\
Took doxycycline for recommended 4 weeks after return & 7 & 32 \\
Applied insect repellent every day & 20 & 91 \\
Applied sun block every day & 4 & 18 \\
Reported health problems while on mission & & \\
Bitten by mosquitoes (2-10 times) & 14 & 64 \\
Fatigue & 13 & 59 \\
Sunburn (not severe) & 8 & 36 \\
Headache & 7 & 32 \\
Sustained an injury & 7 & 32 \\
Anxiety & 5 & 23 \\
Nausea & 3 & 14 \\
Constipation & 1 & 5 \\
Depression & 1 & 5 \\
Thrush & 1 & 5 \\
Stye & 1 & 5 \\
Upper respiratory tract infection & 1 & 5 \\
Reported health concerns while on mission & 1 & 5 \\
Risks associated with earthquakes & 1 & 5 \\
Infections from patients & 1 & 5 \\
Vector-borne disease & 1 & 5 \\
Muns & 1 & 5 \\
Uncertainty about personal insurance & 7 & 5 \\
\hline & & 5 \\
\hline
\end{tabular}


coping problems and noise intolerance (three); diarrhoea (two); and fatigue (one).

\section{Suggestions for prevention}

Several participants offered suggestions for improving conditions for members of subsequent teams. These included prior training and experience, better preparation, access to a packing list, lighter clothes, more logistic support workers, provision of better personal protective equipment and alcohol hand washes, better local sharps containers, more information about earthquakes, more rest and bathing facilities and the opportunity to spend more time with other team members after finishing the mission.

\section{Discussion}

There are several limitations to this study, including incomplete information collected from all team members, the possibility of incomplete recall by participants about health concerns after the event, and perhaps a reluctance to report all concerns to investigators from within the team.

Nonetheless, it appears that CASTA team members remained largely well during the mission to Banda Aceh and in the period immediately following. The provision of safe food and water were likely to be critical in the maintenance of health, and anecdotal reports suggest that the daily debriefing sessions and mutual support among the team's members were helpful in maintaining mental well being.

Travellers to south-east Asia are at risk for a range of illnesses, notably systemic febrile illnesses, diarrhoea, skin disorders, respiratory disorders and malaria. ${ }^{1,2}$ While members of CASTA reported few serious health problems while in Aceh or after the mission was completed, many reported potential health risks, including mosquito bites and failure to complete antimalarial prophylaxis. A small number of participants did report health concerns, mainly sunburn, fatigue and headache, which may have been largely related to time spent unloading and loading equipment at the airfield in hot conditions. The low uptake of immunoglobulin and typhoid vaccine predeparture could be explained by perceived prior immunity to hepatitis $\mathrm{A}$ and typhoid by many team members. Most team members worked indoors while in Aceh, which may explain the low prevalence of sun block use.

Diarrhoea is reported by between $20 \%$ and $60 \%$ of visitors to resource-poor regions. ${ }^{3}$ In comparison, no CASTA members reported gastrointestinal illness. The preventive measures exercised, including the provision of bottled water and ration packs to all members, virtually eliminated exposures to potentially contaminated local materials. As the team experienced several aftershocks from the earthquake of up to the order of seven on the Richter scale, the high rate of concern about earthquakes is entirely understandable. Anxiety among team members was identified as a potential problem by the Australian Government, and following the mission, NSW Health's Centre for Mental Health offered counselling services to all members of the team. The team members who sustained a needle stick injury and eye splash identified no long-term effects.

In an effort to minimise occupational health and safety concerns for future missions, NSW Health has begun a review of the resources to be taken with such a team in the future. It is also reviewing screening tools, including general health and immune status, to help select appropriate team members. It may also be useful to develop a more systematic approach to facilitating the prophylactic use of antimalarials, insect repellent, long sleeved clothing and sun block, possibly through daily sign off by team members reporting compliance. Should a pool of potential team members be developed for future such missions, then systems for maintaining readiness for urgent departure through updated immunisations and training may be useful. Nationally, fact sheets with information about personal safety and health have been prepared for people travelling to and returning from tsunami-affected areas. ${ }^{4,5}$

\section{References}

1. Freedman DO, Weld LH, Kozarsky PE. Spectrum of disease and relation to place of exposure among ill returned travelers. N Engl J Med 2006; 354: 119-30. doi:10.1056/NEJMoa051331

2. Hamur A, Keystone J. Fortnightly review: evaluating fever in travellers returning from tropical countries. BMJ 1996; 312: 953-6.

3. Hill DR. The burden of illness in international travelers. $N$ Engl J Med 2006; 354: 115-7. doi:10.1056/NEJMp058292

4. Australian Government Department of Health and Ageing and Communicable Diseases Network Australia. Health pre cautions for humanitarian workers travelling to tsunamiaffected areas. Updated 2 February 2005. Available at http://www.health.gov.au/internet/wcms/publishing.nsf/ content/phd-tsunami_humanitarian.htm/\$file/ humanitarian_precautions.pdf

5. Australian Government Department of Health and Ageing and Communicable Diseases Network Australia. Health information for relief teams returning from tsunami-affected areas. Updated 2 February 2005. Available at http://www.health.gov.au/internet/wcms/publishing.nsf/ content/phd-tsunami_relief.htm/\$file/relief_teams.pdf 